\title{
Responsabilidade social empresarial: um estudo dos indicadores sociais das empresas brasileiras com foco na tomada de decisão.
}

\section{Corporate social responsibility: a study of social indicators of Brazilian companies focused on decision making.}

\author{
Antonia Wigna de Almeida Ribeiro \\ Universidade Potiguar-UNP \\ Universidade do Estado do Rio Grande do Norte-UERN \\ wignna@hotmail.com
}

Aluna do curso de doutorado em administração da UNP. Mestre em Administração pela UFRN; Especialista em Gestão Empresarial pela FIS; Bacharel em Ciências Contábeis pela UERN. Tem foco em estudos de avaliação de impactos, principalmente no que se refere às políticas públicas. Atualmente trabalha como professora substituta da Universidade do Estado do Rio Grande do Norte

\section{Aletheia Zanow \\ Universidade do Federal do Rio Grande do Norte - UFRN \\ azanow@gmail.com}

Mestre em Administração. pós-graduação em Administração de Empresas - MBA Executivo na Business School São Paulo. Bacharel em Ciências Econômicas.

\section{Ricardo Lima de Medeiros \\ Universidade Federal do Rio Grande do Norte - UFRN \\ ricardomlima@uol.com.br}

Graduação em Filosofia pela Universidade Federal do Rio Grande do Norte (2005) e graduação em Medicina Universidade Federal do Rio Grande do Norte (1984). Mestre em Administração pela Universidade Federal do Rio Grande do Norte e médico ecocardiografista da Universidade Federal do Rio Grande do Norte. Tem experiência na área de Medicina, com ênfase em Cardiologia

\section{RESUMO}

Este artigo avalia a relação entre adoção de práticas de Responsabilidade Social Empresarial (RSE) com a performance organizacional, medida pelo crescimento da receita líquida de empresas brasileiras. Para isso, foi utilizada a metodologia de dados em painel não balanceado para oitenta e oito empresas que divulgaram seus Balanços Sociais no período de 2001 a 2005. Os resultados apontam para uma relação positiva entre RSE e crescimento da receita, o que pode ser fator motivador para que as empresas brasileiras quebrem as barreiras da RSE de forma a obter vantagem competitiva sobre os demais competidores.

Palavras-chaves: Responsabilidade social empresarial. Stakeholders. Vantagem competitiva. Dados em painel. 


\section{ABSTRACT}

This article discusses the relationship between adoption of Corporate Social Responsibility (CSR) practices to organizational performance as measured by growth in net revenues of Brazilian companies. For this, we used the panel data methodology unbalanced to eighty-eight in companies that published their Social Balances from 2001 to 2005. The results show a positive relationship between CSR and revenue growth, which may be a factor motivator for Brazilian companies to break the barriers of CSR in order to gain competitive advantage over other competitors.

Keywords: corporate social responsibility. Stakeholders. competitive advantage. Panel data.

\section{INTRODUÇÃO}

As preocupações com temas relacionados à Responsabilidade Social Empresarial (RSE) existem desde o século XX. Na década de 50, iniciaram-se os primeiros movimentos em favor de uma postura mais ética por parte das organizações. Na ocasião, populares se uniram num movimento de boicote à aquisição de produtos e ações de empresas que tinham ligação com a guerra do Vietnã. Coagidas, e a fim de responder às pressões da sociedade, essas empresas passaram a adotar a prática de divulgação anual dos relatórios que, mais tarde, deram origem ao que é hoje o Balanço Social - BS.

No que se refere à divulgação dessas informações, destaca-se a França como o país pioneiro na determinação da obrigatoriedade da elaboração do balanço social, no fim da década de 70. No Brasil, o primeiro balanço social foi publicado por uma empresa baiana, a Nitrofértil, em 1984. Entretanto, a prática ganhou força a partir da segunda metade da década de 90, ao abranger as dimensões econômica e social, incluindo o termo Responsabilidade Social Empresarial, que integra o desenvolvimento sustentável ambiental, social com crescimento econômico de longo prazo, de forma a mostrar que as corporações devem ir além das obrigações legais e econômicas.

No entanto, divergências entre o interesse dos acionistas, que visam maximizar lucro, e o interesse dos demais grupos, gera um paradoxo para a empresa que tenta atender todos os seus stakeholders. Devido a tantos objetivos conflitantes, a definição de RSE não é sempre tão clara. Friedman (1970) ressaltou que a única responsabilidade de uma unidade de negócios é fechar negócios considerando a dimensão legal de forma a atingir o objetivo da firma, que é maximizar lucros. Davis (1973) argumenta que a responsabilidade social começa somente quando as exigências legais terminam. A contribuição de Carroll (1979) foi a descrição de um modelo piramidal com responsabilidades no âmbito econômico, logo na base da pirâmide, seguindo-se o legal, o ético e, no topo da pirâmide, o filantrópico. Mais tarde 
esse modelo foi complementado pelo que o mesmo chamou de modelo tridimensional, a fim de adaptar melhor à realidade das organizações.

Dessa forma, a elaboração dos relatórios sociais, além de atender os fatores legais, éticos e sociais, passou a ser tratado como instrumento de gestão e avaliação, uma vez que analistas de mercado, investidores e órgãos de financiamento exigem o Balanço Social como um dos documentos necessários à avaliação de riscos e projeções de empresas. Ou seja, sua contribuição extrapola os objetivos do legal, ético e social, incluindo também o econômico, pois agrega valor, no sentido de que traz uma vantagem competitiva e com isso acaba por atrair investidores e amplia a rede de consumidores.

Assim, o conceito de RSE não deve ser confundido com uma concepção baseada na caridade e altruísmo, mas sim numa associação entre responsabilidade social e estratégia empresarial. Poter e Kramer (2006) pontuam que é hora das empresas buscarem esforços para associar suas operações às suas ações sociais visando um contexto mais competitivo, de forma a parar de pensar em termos de "responsabilidade social empresarial" e começar a pensar em termos de "integração social empresarial", que seria integrar o social ao econômico, e assim obter vantagem competitiva.

A realidade mostra que, apesar de algumas empresas ainda serem resistentes a investir em RSE, por acreditar que estes esforços não condizem com maximização de lucros, há uma parcela crescente de empresas que conseguem enxergar oportunidades de gestão, dedicando recursos adicionais a RSE como forma de reconhecer seu papel econômico, ambiental e social no mercado, mesmo não sendo legalmente obrigada a fazê-lo. Tal postura pode ser comprovada com a divulgação dos Balanços Sociais, que apesar de não configurar em obrigatoriedade, tornou sua elaboração e publicação espontânea por determinadas organizações. Com relação a isso, alguns autores (ASHLEY, 2002; CAMPOS e MELO, 2008; ARNT, 2003) defendem que, ao assumir esta prática, as empresas enxergam a possibilidade de retorno financeiro, utilizando as ações sociais como ações estratégicas. O pressuposto passou a ser o de que, as empresas que praticam RSE são mais confiáveis e seus produtos são de alta qualidade (McWILLIAMS e SIEGEL, 2001).

Desde então, o debate no ambiente empresarial é se os gastos em ações sociais e ambientais afetariam a competitividade das empresas. E qual seria o impacto dos investimentos em RSE sobre a rentabilidade das mesmas. Alguns estudos empíricos comprovam uma relação positiva entre RSE e performance econômica e financeira (McGUIRE; SUNDGREN e SCHNEEWEIS, 1988; PRESTON, SAPIENZ e MILLER, 1991; WADDOCK e GRAVES, 1997). Há também, grupos que não identificam qualquer relação 
(AUPPERLE; CARROL e HATFELD,1985; McWILLIAMS e SIEGEL, 2001), e um terceiro, que identificou uma relação negativa ao preço das ações (WRIGHT e FERRIS, 1997).

Diante dessas perspectivas é que a presente pesquisa se propõe a investigar a relação dos investimentos em RSE das empresas brasileiras, verificando o impacto dos investimentos sociais e ambientais na geração de receitas, através de uma análise econométrica com a utilização da metodologia de dados painel.

Além desta seção introdutória, este trabalho apresenta mais cinco seções. A segunda discorrerá sobre o siginificado da terminologia Responsabilidade Social, bem como descreverá modelos de avaliação da responsabilidade social; a terceira tratará da metodologia aqui aplicada. A quarta apresentará os resultados e suas discussões e, por fim, a última seção trará as considerações conclusivas.

\section{REFERENCIAL TEÓRICO}

\subsection{Significado do termo Responsabilidade Social}

O termo Responsabilidade Social Empresarial, amplamente utilizado nos dias de hoje, tem assumido significados diferentes e evolutivos ao longo da história. Na década de 50, o termo era conhecido somente como Responsabilidade Social. O livro de Howard R. Bowen (1953) marcou o início deste debate, pois avaliava as responsabilidades que os homens de negócio (businessmen) deveriam assumir ações que iam além das técnicas e econômicas em prol da sociedade. Outra abordagem que se destaca na literatura é a de Davis (1960), o qual afirma que algumas decisões empresariais que são de responsabilidade social podem ser justificadas se houver um ganho econômico a priori para a empresa, algo como retribuir determinado ganho à sociedade. Em seguida McGuire (1963) completa que os homens de negócio não teriam somente obrigações econômicas e legais, mas também responsabilidades sociais.

Somente no final da década de 60 o termo homens de negócio foi retirado de uso e a responsabilidade social passou a ser vista como uma ação institucional. Para Sethi (1979) e Carroll (1979), o termo abrange três aspectos: obrigação, responsabilidade e responsividade social. Wartick e Cochran (1985) redefiniram as três dimensões da RSE em um modelo de princípios, processos e políticas, argumentando que a definição de Carroll envolve componentes éticos da responsabilidade social e deve ser pensado como princípios, já a 
responsividade social deve ser pensada como processo de resposta social, enquanto a obrigação social deve ser pensada como uma política da empresa. Esta interpretação foi aceita por Carroll (1999).

Todos estes estudos mostram que as empresas têm uma responsabilidade nata de sua atividade econômica, que é produzir bens e serviços para sociedade e, em função de sua efetividade e eficiência, conseguem vendê-los com lucro. Isso é o que a sociedade espera das empresas. Em seguida espera, como regra básica do negócio, que as empresas sigam as leis, o que vai ao encontro da definição de Carroll $(1979,1991)$ sobre responsabilidade social, sendo a motivação econômica a base da existência de uma empresa, e, em segundo plano, a responsabilidade legal. O terceiro e quarto componentes seriam os comportamentais, isto é, aquele que estão de acordo com as expectativas da sociedade (como a ética, por exemplo). O quarto é o discricionário, que mais tarde Carroll (1991) define como filantrópico. Assim, Carroll (1991) resume que a empresa deve se esforçar para fazer lucro, ser obediente à lei, ser ético e ser um bom cidadão corporativo.

\subsection{Modelos Teóricos de Avaliação da Responsabilidade Social}

A década de 80 marca a evolução dos estudos da RSE em termos de resultado empírico, com destaque para o trabalho de Aupperle, Carroll e Hatfield (1985) que avalia a relação entre RSE e lucratividade, sendo este um dos primeiros trabalhos a utilizar o constructo teórico de RSE para mensurá-lo na prática. O estudo confirmou a prioridade dos quatro componentes da definição de Carroll (1979), na seguinte ordem: econômica, legal, ética e discricionária. Muitos, no entanto, não enxergam a reponsabilidade econômica como parte da definição de responsabilidade social, e sim como algo inerente ao negócio, mas que a orientação social de uma empresa pode ser avaliada observando a importância que os componentes não-econômicos (legal, ético e filantrópico) têm comparado com o econômico (AUPPERLE; CARROL e HATFELD,1985).

Desde então, diversos modelos teóricos têm sido utilizados para avaliar a Responsabilidade Social Empresarial. Friedman (1970) utilizou a Teoria da Agência, que avalia o conflito de interesses dos gerentes e acionistas (shareholders), onde o objetivo da firma é unicamente atender a legislação para maximização de lucro.

Outros autores também buscaram fundamentação teórica na Teoria da Agência como Preston (1978) e em seguida Carroll (1979). De acordo com Carroll (1983), RSE envolve uma 
conduta de negócio que deve ser economicamente lucrativa, cumpridora da legislação, ética e socialmente solidária.

Em seu terceiro trabalho de destaque, Carroll (1991) idealiza os componentes da RSE e como eles estariam relacionados em um modelo piramidal. Para o autor, a performance econômica é a base que suporta todos os outros componentes: legal, ético e filantrópico respectivamente, como mostra a Figura 1. Embora a firma seja a unidade econômica básica da sociedade, ela tem também outras responsabilidades que são obrigações para com a sociedade. Neste momento, Carroll (1991) utiliza a teoria dos stakeholders (FREEMAN, 2001), que personaliza o "social” da RSE, delineando os grupos específicos que devem ser considerados na orientação da RSE.

\section{Figura 1 - Pirâmide de RSC segundo Carroll}

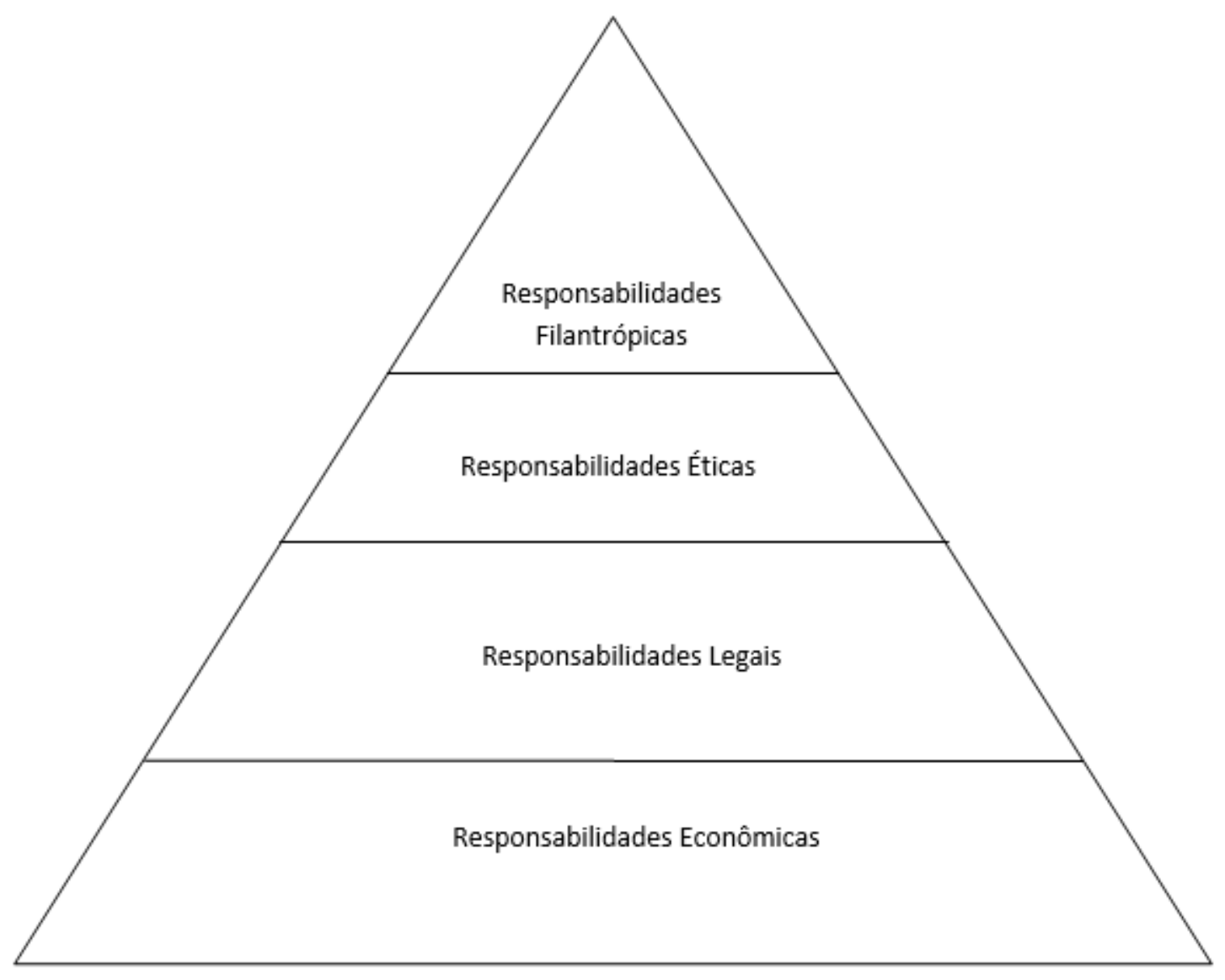

Fonte: Adaptado de Carroll (1991).

Ou seja, independente da estratégia de gestão, a força da globalização mostra que incorporar o modelo proposto por Carrol (1991) aumenta a capacidade do modelo de 
governança corporativa em articular os interesses dos acionistas com os interesses dos stakeholders.

O presente artigo se baseia no pressuposto básico da Teoria da Agência, assumindo que as empresas visam maximizar seus lucros de forma a aumentar a riqueza do acionista (Jensen, 1988). Desta forma a RSE pode ser vista como um tipo de investimento, de forma a se diferenciar no mercado em que atua e a obter vantagem competitiva (McWILLIAMS e SIEGEL, 2001; PORTER e KRAMER, 2006).

\section{ESTRATÉGIA EMPÍRICA, DADOS E FONTES}

A fim de captar a relação entre os indicadores socioambientais na obtenção de receitas auferidas pelas organizações em estudo, este trabalho utiliza a metodologia de dados em painel, por esta capaz de investigar um conjunto de indivíduos em mais de um período de tempo. A definição de dados em painel engloba dois conceitos essenciais à compreensão: Dados de Cortes Transversais (cross-section) - que reúne em uma amostra informações tomadas em um determinado ponto do tempo -, e Dados de Séries Temporais - que consiste num conjunto de observações sobre uma ou mais variáveis ao logo do tempo. Sendo assim, "um conjunto de dados em painel (ou dados longitudinais) consiste em uma série temporal para cada registro de corte transversal do conjunto de dados" (WOOLDRIDGE, 2010. P. 10), de forma que, as mesmas unidades de corte transversal são acompanhas ao longo do tempo.

De acordo com Greene (2003), um modelo de regressão com dados em painel deverá seguir essa estrutura:

$$
Y_{i t}=X^{\prime}{ }_{i t} \beta+Z_{i}^{\prime} \alpha+\epsilon_{i t}
$$

Onde $Y_{i t}$ é o valor da variável dependente; $\boldsymbol{X}_{i t}$ contém $\mathrm{K}$ regressores que representam os valores do conjunto de variáveis explicativas; $\boldsymbol{\beta}$ corresponde ao conjunto de parâmetros a serem estimados; $\boldsymbol{\epsilon}_{\boldsymbol{i} \boldsymbol{t}}$ são os erros aleatórios; $\boldsymbol{i}$ e $\boldsymbol{t}$ denotam a unidade observacional e o período de cada variável, respectivamente.

Esta técnica apresenta a vantagem de redução de colinearidade entre as variáveis explicativas, como também permite trabalhar o maior número de observações e o tratamento estático e dinâmico das relações de interesse. A utilização da técnica de dados em painel, neste caso, desbalanciado, se justifica pelo fato de o banco de dados do IBASE, para algumas empresas da amostra, não disponibilizar todas informações em todos os períodos estudados.

Assim, para atender tal objetivo, este trabalho faz o uso da seguinte equação: 


$$
R L_{i t}=\beta_{0}+\beta_{2} I S I_{i t}+\beta_{3} I S E_{i t}+\beta_{4} I A_{i t}+\beta_{5} \text { Selic }_{t}+\beta_{6} I n f_{t}+\beta_{7} P I B_{t}+\beta_{8} C_{a m b}+v_{i t}
$$

Onde $R L_{i t}$ é a receita líquida da $i$-ésima organização no período $t ; I S I_{i t}$ é o indicador social interno da i-ésima organização no período t; $I S E_{i t}$ é o indicador social externo da iésima organização no período t; $I A_{i t}$, é o indicador ambiental da da i-ésima organização no período t; Selic $_{i t}$, é a taxa de juros selec no período t; $I n f_{i t}$ é a taxa de inflação acumulada no período t, $P I B_{t}$ é produto Interno Bruto no período $t ; C a m b_{i t}$, é a taxa de câmbio no período t; e $v_{i t}$ são os erros aleatórios e os $\beta$ 's são os parâmetros a serem estimados.

No que se refere aos indicadores, os indicadores sociais internos (ISI) compõem os gastos despendidos em favor dos funcionários com alimentação, encargos sociais compulsórios, previdência privada, saúde, segurança e medicina no trabalho, educação, cultura, capacitação e desenvolvimento profissional, creches ou auxílio-creche, participação nos lucros ou resultados, além de outros.

Os indicadores sociais externos (ISE) são compostos pelos gastos em favor da sociedade, tais como educação, cultura, saúde e saneamento, habitação, esporte, lazer e diversão, creches, alimentação, combate à fome e segurança alimentar e outros, além dos tributos (exceto encargos sociais).

Os investimentos relacionados com a produção/operação da empresa e investimentos em programas e/ou projetos externos, compõem os indicadores ambientais (IA), ou seja, o total de investimentos em meio ambiente.

Dito isso, o painel de dados corresponde às informações sobre a receita líquida; os valores representativos dos indicadores sociais internos, indicadores sociais externos e os indicadores ambientais, medidos em valores monetários; a taxa de juros selic; a taxa de inflação acumulada; o PIB; e a taxa de câmbio ${ }^{1}$. A amostra corresponde às 88 empresas que publicaram seus balanços sociais nos períodos de 2001 a 2005. A utilização do referido intervalo temporal justifica-se pelo fato de que se buscou analisar os períodos mais recentes. No entanto, verificou-se que os balanços publicados até a presente data vão até o período de 2008, sendo que de 2006 a 2008 há um número consideravelmente reduzido de organizações que disponibilizaram suas informações em relação ao período de 2001 a 2005. As

\footnotetext{
${ }^{1}$ As variáveis PIB, Taxa de Juros Selic, Inflação e Taxa de Câmbio são consideradas como determinantes da rentabilidade e foram utilizadas nas pesquisas de Demirgüç-Kunt e Huizinga (1999); Dick (1999); Jiang et al (2003); Hasan e Bashir (2003); Pasiouras e Koumidou (2007); Pasiouras e Koumidou (2007); Athanasoglouet al. (2008); Catão (1998); Havrylchyk e Jurzyk (2006).
} 
informações aqui contidas foram coletadas a partir do banco de dados IBASE e Instituto Brasileiro de Geografia e Estatística - IBGE.

Os efeitos esperados das variáveis sobre a receita líquida seguem como indicado na Tabela 1.

Tabela 1 - Efeitos esperados

\begin{tabular}{cc}
\hline Variável & Expectativa \\
\hline Indicador Social Interno & + \\
Indicador Social Externo & + \\
Indicador Ambiental & + \\
Selic & $+/-$ \\
Inflação & - \\
PIB & + \\
Taxa de Câmbio & + \\
\hline
\end{tabular}

Fonte: elaboração própria

A expectativa quanto aos efeitos relativos aos indicadores sociais internos e externos, e o indicador ambiental é de que seja positivo, apesar do gasto despendido pelas organizações na promoção do bem-estar social daqueles afetados direta ou indiretamente por suas ações. Quanto a isso, encontram-se na literatura teorias, como a de Friedman (1970), que contra argumentam essa expectativa, cuja visão inerente a tais investimentos é de que, ao arcar com esses gastos as empresas perdem no quesito competitividade.

No entanto, a presente pesquisa segue a mesma linha de pensamento de autores que esperam uma relação positiva, como é o caso de Waddock e Graves (1997), Preston e O’Bannon (1997), Tiras, Ruff e Brown (1998). O fato de não haver uma obrigatoriedade de divulgação das informações quanto à sua postura socioambiental e, mesmo assim, encontramse divulgados balanços sociais tanto de sociedades de capital aberto ${ }^{2}$, quanto daquelas cujas exigências legalmente obrigatórias são mais flexíveis, as de capital fechado ${ }^{3}$, levanta a hipótese de que há uma estratégica na aquisição de benefícios.

No que se refere às expectativas das variáveis PIB e Câmbio, espera-se que a base tributária exerça uma ação positiva sobre as receitas, já que esta variável é responsável por captar a renda das pessoas, e, portanto, espera-se que quanto maior a renda, maior o poder de

\footnotetext{
${ }^{2}$ Exemplos de sociedades anônimas que divulgaram balanços sociais: Embasa S/A; Brasilcap Capitalização S/A e Alunorte S/A;

${ }^{3}$ Empresas de capital fechado que têm balanços sociais divulgados: Agro Pecuária Mongre Ltda; Venbo Comércio de Alimentos Ltda (BOBS) e AMG Engenharia, entre outras.
} 
compra, assim como a taxa de câmbio, que ao sofrer uma variação positiva, os preços dos produtos tendem a cair, favorecendo assim às exportações. Dessa forma, empresa que já tem sua demanda interna ganha em demanda externa, alavancando suas vendas.

Para variável Selic espera-se dois efeitos distintos. Como cita Primo et al (2013), taxas de juros elevadas favorecem a rentabilidade das instituições financeiras. Por outro lado, esse mesmo aumento reduz o valor de mercado dos títulos pré-fixados, o que pode ocasionar aumento do custo de captação de recurso. Portanto, espera-se que um aumento na taxa de juros selic exerça um efeito positivo sobre a receita líquida, uma vez que a amostra contida nesta pesquisa conta com instituições financeiras e empresas cujas atividades estão voltadas ao fornecimento de bens e serviços. Assim, aumentando a taxa de juros, há a possibilidade de ganhos auferidos tanto nas transações financeiras, como é o caso de concessão de crédito, quanto na aquisição receita financeira, como o recebimento de juros ativos decorrentes de atraso no recebimento de clientes. No entanto, há também a possibilidade de um efeito negativo: Um aumento na taxa de juros pode reduzir a demanda, e como consequência, diminuir as vendas.

No que se refere à variável inflação, conforme Primo et al (2013), seu efeito dependerá do volume de ativos e passivos sujeitos à desvalorização. Em suma, expectativa é de que um aumento na inflação possa impactar positivamente no preço e, por consequência, reduzir o poder de compra, de forma a relacionar-se negativamente com as receitas de venda.

Justificadas as expectativas da tabela 1, a próxima seção apresentará os resultados oriundos da aplicação do modelo dados em painel sobre as variáveis em questão.

\section{RESULTADOS}

A aplicação do modelo em busca de captar os efeitos dos indicadores socioambientais, e ainda os da taxa de juros, inflação, PIB e taxa de câmbio, direcionou esta pesquisa aos resultados apresentados na tabela 2 .

Tabela 2 - Resultado das Estimações

\begin{tabular}{ccc}
\hline & Variável Dependente: RL & \\
\hline Variável Explicativa & Coeficiente \\
\hline \multirow{2}{*}{$I S I$} & $8,246^{* *}$ \\
& $(3,794)$ \\
\multirow{2}{*}{$I S E$} & $1.105^{*}$ \\
& & $(0,348)$ \\
IA & $6.703^{* *}$ \\
Selic & $(2,833)$ \\
\hline
\end{tabular}




\begin{tabular}{cc}
\hline & \\
Inf & $(39145.58)$ \\
& $-57642.96 * * *$ \\
PIB & $(31269.03)$ \\
& -0.347 \\
Camb & $(0.618)$ \\
Cons & $523880.7 * *$ \\
$N^{2}=419$ & $(201512.8)$ \\
Wald $\left(\chi^{2}\right)=1839.08$ & -1080785 \\
$\mathbf{p}-\mathbf{v a l o r}\left(\chi^{\mathbf{2}}\right)=0,000$ & $(1195673)$ \\
\hline
\end{tabular}

Fonte: elaboração própria

De acordo com as estimativas e seus respectivos erros padrão, verifica-se que todas as variáveis, exceto à que se refere ao PIB, mostraram-se significativas a pelo menos $10 \%$. O destaque vai para a variável do indicador social externo, com significância estatística de $1 \%$, seguida das variáveis representativas dos indicadores sociais internos e ambientais, que se mostraram estatisticamente significantes a $5 \%$. Além disso, ressalta-se o poder de explicação do conjunto das variáveis explicativas, dada sua significância expressa pelo elevado valor da estatística de Wald. Assim, pode-se assumir que o conjunto de variáveis utilizado para construir a função da Receita Líquida é capaz de explicar individual e conjuntamente as variações observadas para a referida série durante o período analisado.

No que se refere às variáveis de controle, demonstraram significância estatística as variáveis Selic, Inf e Camb, com significância de 10\%,10\% e 5\%, respectivamente. Já a variável PIB mostrou-se não significativa, inclusive a 10\%. No entanto, optou-se por deixá-la no modelo, evitando assim problemas de viés, já que esta é repetitivamente considerada em pesquisas desta natureza ${ }^{4}$ por captar o desenvolvimento econômico de uma região.

Para a variável Selic constatou-se um efeito positivo sobre as receitas líquidas. O parâmetro associado à variável reflete um impacto de $\mathrm{R}$ \$ 73.327,90 sobre a receita líquida da organização para cada $1 \%$ de variação positiva na taxa de juros. Ou seja, das receitas auferidas pelas empresas em estudo, aproximadamente $1,76 \%$ são captadas no recebimento de juros ativos, dada uma média de $\mathrm{R} \$ 4.171 .592 .000,00$ de receitas líquidas adquiridas.

Como esperado, a variável inf apresentou-se com um efeito negativo. Assim, para cada $1 \%$ de aumento na inflação, verifica-se um déficit de $\mathrm{R}$ \$ 57.642,96 na receita líquida. Já para a variável $c a m b$ percebe-se que a mesma exerce um impacto positivo sobre as vendas, ou seja, para cada aumento de $1 \%$ verificado na taxa de câmbio, há um aumento de $\mathrm{R} \$$

${ }^{4}$ Demirgüç-Kunt e Huizinga (1999); Dick (1999); Jiang et al. (2003); Hasan e Bashir (2003); Pasiouras e Koumidou (2007); e outros. 
523.880,70 nas receitas líquidas. O parâmetro associado à variável mostrou uma significância de $5 \%$.

Quanto às variáveis de interesse, a estimativa para o Indicador Social Interno (ISI) confirma a expectativa de um efeito positivo sobre a Receita Líquida - RL, ou seja, o valor encontrado para o parâmetro associado a este indicador expressa a compreensão de que para cada R \$1,00 gasto em favor do funcionário, no que se refere à alimentação, saúde, educação, entre outros, tem-se um aumento de $\mathrm{R} \$$ 8.246,00 nas Receitas Líquidas da organização. Da mesma forma, confirmam-se os efeitos esperados para os Indicadores Sociais Externos (ISE) e Indicadores Ambientais (IA). Conforme a tabela 2, para cada $\mathrm{R} \$ 1,00$ investido no bem-estar da sociedade, como é o caso de gasto com saneamento, habitação, combate à fome e segurança alimentar, como também os gastos investidos em prol do meio ambiente, tem-se um aumento de aproximadamente $\mathrm{R} \$ 1.105,00$ e $\mathrm{R} \$ 6.703,00$, respectivamente, nas Receitas Líquidas.

No que se refere aos indicadores socioambientais como um todo, seus resultados ratificam a ideia defendida por Campos e Melo (2008), Arnt (2003), Ashley e Cardoso (2002), de que investimentos em prol do bem estar social podem ser uma prática estratégica para competitividade e geração de lucro das empresas. Resultado equivalente foi percebido na pesquisa de Milani et al (2012), que verificou um menor risco e maior retorno financeiro para aqueles que decidem investir em empresas com melhores práticas de sustentabilidade, governança corporativa e responsabilidade social.

\section{CONCLUSÃO}

O termo Responsabilidade Social Empresarial é visto ao longo da história com diferentes significados e abordagens, abrangendo desde o que a firma faz em prol da sociedade, de forma obrigatória ou voluntária, até quais as consequências sociais dos produtos e serviços por ela produzidos. Trata-se de visões que dependem do ponto de vista dos interesses de cada stakeholder, mas que tem em comum o fato de entenderem o papel econômico das empresas e exigir dela uma postura ética em relação às suas ações perante a sociedade.

A obtenção de lucro por si só não significa que foi alcançado algum objetivo social, pois este pode simplesmente ser distribuído entre os acionistas e principais stakeholders da empresa. O aspecto econômico da responsabilidade social pode ocorrer de dois modos distintos. Parte desse lucro pode ser deliberadamente direcionado para a realização de ações 
sociais, como visto nos indicadores internos e externos estudados no presente artigo. De outra maneira, o próprio produto ou serviço da empresa pode ser um agente beneficiador para a população, e desta forma o social estaria estrategicamente integrado ao econômico. Hospitais e empresas especializadas em despoluição de rios são exemplos desse tipo de ação. O conhecimento dos benefícios trazidos para a corporação (lucro ou benefícios estratégicos) pode ser fator motivador para que os gerentes passem a incluir em suas agendas ações e programas relacionados à responsabilidade social. Caso fique clara a relação positiva entre ações de responsabilidade social e ganhos para sua empresa, o gestor, focado nos resultados da empresa e com obrigações para com os sócios e acionistas, não poupará esforços para que suas ações sejam traduzidas em lucro, em benefícios estratégicos ou em vantagem competitiva.

Neste sentido, a presente pesquisa pode influenciar nesta decisão, pois evidencia que o investimento em ações voltadas ao bem estar social tem relação positiva com os resultados financeiros das organizações ora estudadas, dadas as significâncias estatísticas e os resultados positivos dos parâmetros associados às variáveis representativas dos mesmos. Além disso, o impacto destes sobre a receita líquida auferida aproxima-se da casa dos 0,4\%. Juntos, os indicadores socioambientais representam em média $0,38 \%$ das receitas líquidas das empresas contidas na amostra.

Por fim, é importante ressaltar que, se algum gestor direciona suas atividades para o âmbito da responsabilidade social apenas visando o benefício que ele pode garantir para sua empresa, ele está deixando em segundo plano o verdadeiro benefício que pode proporcionar à população. Isso leva de certa forma a um questionamento quanto à dimensão ética, uma vez que permite prever que, caso não houvesse vantagem para o próprio empreendimento, também não haveria interesse da empresa em trazer outros tipos de benefícios à população. A julgar pelo fato de ainda não existirem trabalhos que comprovem ou quantifiquem esse retorno financeiro, essa não deve ser a forma de pensar da maioria dos gestores de empresas na atualidade.

\section{REFERÊNCIAS}

ATHANASOGLOU, Panayiotis P.; BRISSIMIS, Sophocles N.; DELIS, Matthaios D. Bankspecifi c, industry-specifi c and macroeconomic determinants of bank profi tability. Journal of International Financial Markets, Institutions \& Money, 18(2):121-136. 2008.

ARNT, R. Responsabilidade social: Questão de coerência. Revista Exame. São Paulo, p. 7476, maio 2003. 
ASHLEY, Patrícia A.; CARDOSO, J. G. A responsabilidade social nos negócios: um conceito em construção. In: ASHLEY, P. A. (Coord.). Ética e Responsabilidade Social nos Negócios. São Paulo: Editora Saraiva, p.2-16. 2002.

AUPPERLE, Kenneth E.; CARROLL, Archie B.; HATFIELD, John D. An empirical examination of the relationship between corporate social responsibility and profitability. Academy of management Journal, v. 28, n. 2, p. 446-463, 1985. BOWEN, Howard R.; JOHNSON, F. Ernest. Social responsibility of the businessman. Harper, 1953.

CAMPOS, Lucila Maria de Souza; MELO, Daiane Aparecida de. Indicadores de Desempenho dos sistemas Gestão Ambiental (SGA): uma pesquisa teórica. Revista Production. Vol. 18, $n^{\circ}$ 3. São Paulo, 2008.

CARROLL, Archie B. A three-dimensional conceptual model of corporate performance. Academy of management review, v. 4, n. 4, p. 497-505, 1979.

CARROLL, Archie B.Corporate social responsibility: Will industry respond to cutbacks in social program funding. Vital Speeches of the day, v. 49, n. 19, p. 604-608, 1983.

CARROLL, Archie B. The pyramid of corporate social responsibility: Toward the moral management of organizational stakeholders. Business horizons, v. 34, n. 4, p. 39-48, 1991.

CARROLL, Archie B. Corporate social responsibility evolution of a definitional construct. Business \& society, v. 38, n. 3, p. 268-295, 1999.

CATÃO, Mr Luis. Intermediation Spreads in a Dual Currency Economy: Argentina in the 1990's. International Monetary Fund, 1998.

DAVIS, Keith.Can business afford to ignore social responsibilities? California Management Review, v. 2, n. 3, 1960.

DAVIS, Keith. The case for and against business assumption of social responsibilities. Academy of Management journal, v. 16, n. 2, p. 312-322, 1973.

DEMIRGÜÇ-KUNT, Ash; HUIZINGA, Harry. Determinants of Commercial Bank Interest Margins and Profi tability: some international evidence. World Bank Economic Review, 13(2):379-408. 1999.

DICK, Astrid. Banking Spreads in Central America: Evolution, Structure and Behavior. Harvard Inst. for Internat. Development, 1999.

FLAMINI, Valentina; SCHUMACHER, Miss Liliana; MCDONALD, Mr Calvin A. The determinants of commercial bank profitability in Sub-Saharan Africa. International Monetary Fund, 2009.

FREEMAN, R. Edward; MCVEA, John. A stakeholder approach to strategic management. 2001.

FRIEDMAN, Milton. The social responsibility of business is to increase its profits. springer berlin heidelberg, 2007. 
HASSAN, M. Kabir; BASHIR, Abdel-Hameed M. Determinants of Islamic banking profitability. In: 10th ERF Annual Conference, Morocco. 2003. p. 16-18.

OLENA HAVRYLCHYK, CEPII; JURZYK, Paris Emilia. Profitability of foreign and domestic banks in Central and Eastern Europe: does the mode of entry matter?. 2005.

JIANG, G. et al. Determinants of bank profitability in Hong Kong. Hong Kong Monetary Authority Quarterly Bulletin, v. 2003, p. 5-14, 2003.

MCGUIRE, Joseph William. Business and society. McGraw-hill, 1963.

MCGUIRE, Jean B.; SUNDGREN, Alison; SCHNEEWEIS, Thomas. Corporate social responsibility and firm financial performance. Academy of management Journal, v. 31, n. 4, p. 854-872, 1988.

MCWILLIAMS, Abagail; SIEGEL, Donald. Corporate social responsibility: A theory of the firm perspective. Academy of management review, v. 26, n. 1, p. 117-127, 2001.

MILANI, Bruno; RIGHI, Marcelo Brutti; CERETTA, Paulo Sergio; DIAS, Valria da Veiga. Práticas de Sustentabilidade, Governança Corporativa e Responsabilidade Social afetam o risco e o retorno dos investimentos? Revista de Administração da UFSM, v. 5, p. 667-682, 2012.

PASIOURAS, Fotios; KOSMIDOU, Kyriaki. Factors influencing the profitability of domestic and foreign commercial banks in the European Union. Research in International Business and Finance, v. 21, n. 2, p. 222-237, 2007.

PORTER, Michael E.; KRAMER, Mark R. The link between competitive advantage and corporate social responsibility. Harvard business review, v. 84, n. 12, p. 78-92, 2006.

PRESTON, Lee E. Analyzing Corporate Social Performance-Methods and Results. Journal of Contemporary Business, v. 7, n. 1, p. 135-150, 1978.

PRESTON, Lee E.; O'BANNON, Douglas P. The corporate social-financial performance relationship. Business and society, v. 36, n. 4, p. 419-429, 1997.

PRESTON, Lee E.; SAPIENZA, H. J.; MILLER, R. D. Stakeholders, shareholders, managers: Who gains what from corporate performance.Socio-economics: Toward a new synthesis, v. 149 , p. $65,1991$.

PRIMO, Uverlan Rodrigues; DANTAS, José Alves; MEDEIROS, Otávio Ribeiro; CAPELLETTO, Lúcio Rodrigues. Determinantes da Rentabilidade Bancária no Brasil. Revista de Administração e Contabilidade da Unisinos. Vol. 10, nº 14. 2013. Disponível em:

file:///C:/Users/wigna/Downloads/Primo_Dantas_Medeiros_Capelletto_2013_Determinantesda-rentabilidade 18185\%20(1).pdf. Acesso em: 25 jan 2015.

SETHI, S. Prakash. A conceptual framework for environmental analysis of social issues and evaluation of business response patterns. Academy of Management Review, v. 4, n. 1, p. 6374,1979 

dos indicadores sociais das empresas brasileiras com foco na tomada de decisão. Revista Unemat de

TIRAS, Samuel L.; RUF, Bernadette M.; BROWN, Robert M. The relation between stakeholders' implicit claims and firm value. Available at SSRN 141342, 1998.

WADDOCK, Sandra A.; GRAVES, Samuel B. The corporate social performance-financial performance link. Strategic management journal, v. 18, n. 4, p. 303-319, 1997.

WARTICK, Steven L.; COCHRAN, Philip L. The evolution of the corporate social performance model. Academy of management review, v. 10, n. 4, p. 758-769, 1985.

WRIGHT, Peter; FERRIS, Stephen P. Agency conflict and corporate strategy: The effect of divestment on corporate value. Strategic management journal, v. 18, n. 1, p. 77-83, 1997. 